\title{
Disclosure: Psychology Changes Everything
}

\section{Citation}

George Loewenstein, Cass R. Sunstein \& Russell Golman, Disclosure: Psychology Changes Everything, 6 Ann. Rev. Econ. 391 (2014).

\section{Published Version}

http://www.annualreviews.org/doi/abs/10.1146/annurev-economics-080213-041341

\section{Permanent link}

http://nrs.harvard.edu/urn-3:HUL.InstRepos:16217274

\section{Terms of Use}

This article was downloaded from Harvard University's DASH repository, and is made available under the terms and conditions applicable to Open Access Policy Articles, as set forth at http:// nrs.harvard.edu/urn-3:HUL.InstRepos:dash.current.terms-of-use\#OAP

\section{Share Your Story}

The Harvard community has made this article openly available.

Please share how this access benefits you. Submit a story.

\section{Accessibility}




\title{
Disclosure: Psychology Changes Everything
}

\author{
George Loewenstein \\ Department of Social and Decision Sciences, Carnegie Mellon University \\ gl20@andrew.cmu.edu \\ Cass R. Sunstein \\ Harvard Law School \\ csunstei@law.harvard.edu \\ Russell Golman \\ Department of Social and Decision Sciences, Carnegie Mellon University \\ rgolman@andrew.cmu.edu
}

For inclusion in Annual Review of Economics

\begin{abstract}
We review literature examining the effects of laws and regulations that require public disclosure of information. These requirements are most sensibly imposed in situations characterized by misaligned incentives and asymmetric information between, for example, a buyer and seller or an advisor and advisee. We review the economic literature relevant to such disclosure, and then discuss how different psychological factors complicate, and in some cases radically change, the economic predictions. For example, limited attention, motivated attention, and biased assessments of probability on the part of information recipients can significantly diminish, or even reverse, the intended effects of disclosure requirements. In many cases disclosure does not much affect the recipients of the information, but does significantly affect the behavior of the providers, sometimes for the better and sometimes for the worse. We review research suggesting that simplified disclosure, standardized disclosure, vivid disclosure, and social comparison information can all be used to enhance the effectiveness of disclosure policies.
\end{abstract}

Acknowledgments: We thank Saurabh Barghava, Cynthia Estlund and Daniel Schwartz for helpful comments, and Jacob Reisberg and Spencer Baugh for superb research assistance.

Keywords: Mandatory Disclosure, Regulation, Behavioral Economics, Nudges, Telltale Heart Effect, Moral Licensing 


\section{Introduction}

Mandatory disclosure of information - "targeted-transparency" (Fung, Graham \& Weil, 2013) -- is among the most ubiquitous and least controversial elements of public policy, often promoted as an attractive alternative to so-called 'hard' forms of regulation. Who can oppose low-cost policies designed to provide health and safety warnings to workers, energy efficiency information to consumers, privacy information to those giving personal data to companies over the web, or disclosure of the financial risks associated with investments, home mortgages, credit cards and auto loans? Despite a paucity of data supporting the efficacy of such policies, information disclosure has been broadly advocated as an appropriate response to a wide range of social and economic problems (e.g., Bebchuk \& Jackson, 2013; Kleindorfer \& Orts, 1998; Lansky, 2002; Sage, 1999).

An important advantage of informational, as opposed to 'harder' forms of regulation, is its flexibility and respect for the operation of free markets. Regulatory mandates are blunt swords; they tend to neglect heterogeneity and may have serious unintended adverse effects. For example, energy efficiency requirements for appliances may produce goods that work less well or that have characteristics that consumers do not want (Allcott \& Greenstone, 2012). Information provision, by contrast, respects freedom of choice. If restaurant patrons are informed of the calories in their meals, those who want to lose weight can make use of the information, leaving those who are unconcerned about calories unaffected. If automobile manufacturers are required to measure and publicize the safety characteristics of cars, potential car purchasers can trade safety concerns against other attributes, such as price and styling. Disclosure does not interfere with, and should even promote, the autonomy (and quality) of individual decision making. If properly designed, it should also increase efficiency, helping to avoid cases of market failure resulting from incomplete and asymmetric information coupled with misaligned incentives (e.g., Akerlof, 1970; Ross, 1973).

Standard economic theory offers several explanations for why the provision of information occurring 'naturally,' as a function of market forces, may be suboptimal. Although there are active markets for some types of information, much of the information provided in disclosures (e.g., product risk warnings, financial disclosures, or nutrition facts labels) can be viewed as quasi-public goods that, due to the free-rider problem, may be under-provided relative to the 
social optimum. For example, even if myriad fast food patrons will benefit from calorie posting, it is unlikely to be worth any one patron's time or money to devote much effort to seeking disclosure of the calorie content of menu offerings.

The cost of providing the information (including the cost of enforcing disclosure regulations) is, of course, a legitimate consideration (Jovanovic, 1982). Mandatory disclosure can be justified by an efficiency argument when the societal gains from information provision outweigh the societal costs (Coffee, 1984). A comprehensive accounting of costs, moreover, should include the time that people need to process the information, the opportunity costs of distracting attention from existing information, and even, in some cases, the hedonic cost of dealing with the information. Graphic cigarette warning labels, for example, might seem to be low cost, but they may well reduce the utility of people who continue to smoke (Loewenstein \& O’Donoghue, 2006), and, at least in principle, that loss should be taken into account. The same is true of requirements to disclose the caloric content of food, which will have negative hedonic consequences for those who continue to eat high calorie foods.

Given the potential benefits and often low cost of information disclosure, it should come as no surprise that disclosure policies have proved highly attractive to legislators and regulators (Sunstein, 1999). The Credit Card Accountability Responsibility and Disclosure Act of 2009, the Affordable Care Act, and the Dodd-Frank Wall Street Reform and Consumer Protection Act are all packed with disclosure requirements. The same is true of the Sarbanes-Oxley Act (implemented in the aftermath of highly publicized accounting irregularities following the failure of companies such as Enron and WorldCom), as Ripken (2006) notes in an insightful article. In several of its sections, the act does not ban or require certain corporate or auditor practices, but instead mandates disclosure. For example, it does not require corporations to include financial experts on their boards of directors, but requires firms to disclose whether they have, and if not, to explain why not. Similarly, it does not require corporations to adopt a code of ethics for senior financial officers but, if no ethics code is adopted, requires corporations to disclose why they failed to do so.

The ubiquity of disclosure is documented forcefully and amusingly in a paper by BenShahar and Schneider (2010) titled, provocatively, “The Failure of Mandated Disclosure.” The authors devote twelve pages of their paper to listing some of the numerous and sometimes absurd disclosure requirements embedded in federal and state statutes, administrative regulations, and 
court rulings, and applying to virtually all types of loans, bank accounts, mutual funds, creditcards, securities brokers, credit-reporting agencies, investment advisors, ATMs, pawnshops, payday loans, rent-to-own contracts, installment-sales, all types of insurance contracts, vehicle rentals, self-storage facilities, car-towing companies, car-repair shops, and much more. Perhaps the most amusing (if somewhat macabre) example is the requirement that funeral operators in California disclose to casket purchasers that "THERE IS NO SCIENTIFIC OR OTHER EVIDENCE THAT ANY CASKET WITH A SEALING DEVICE WILL PRESERVE HUMAN REMAINS.”

Perusal of this list suggests a common pattern in situations in which mandatory disclosure requirements are imposed. In general, such requirements are applied when less informed consumers interact with better informed sellers, and when the incentives of the consumers and sellers are at least arguably misaligned. (Note that in many important cases the sellers and consumers are providers and recipients of advice.) These features characterize situations such as:

- interactions between an automobile seller and potential customer. The seller has better information about the safety of the cars it sells, but the customer may have a greater interest in driving a safe car.

- interactions between a chain restaurant and its patrons. The restaurant has better information about the nutritional properties of the food it sells, but the customer may have a greater interest in eating nutritious food.

- interactions between a physician and a patient. The physician has better information about the appropriateness of different tests and treatments, but may also have incentives to recommend specific tests, drugs, or services (such as surgery) that may not be in the patient's best interest.

- interactions between manufacturers who 'outsource' production to establishments that mistreat workers or engage in environmentally destructive patterns of behavior, and consumers who, while appreciating low prices, have a desire to consume 'green' or socially conscientious products. 
In what follows, we focus on these types of situations, characterized by misaligned incentives and asymmetric information, often referring to the consumers and sellers as, respectively, the “demand side" and "supply side” of the interaction.

In addition to situations in which disclosure addresses standard economic market failures created by asymmetric information and misaligned incentives, we examine situations in which disclosure serves the purpose of helping to protect consumers against themselves. Psychology and behavioral economics provide a new rationale for regulation that supplements traditional economic accounts (Camerer et al., 2003; Sunstein \& Thaler, 2003). The new rationale involves what might be called "behavioral market failures” (Sunstein, 2014). Analogous to the concept of externalities in standard economics, behavioral economics enlarges the potential scope of justifiable regulation by introducing the concept of internalities - costs that individuals impose on themselves but fail to internalize at the time of decision (Gruber \& Koszegi, 2001; Herrnstein et al., 1993).

Note that internalities alone do not provide a rationale for mandatory disclosure regulations; at least some kind of misalignment of incentives is important in this case as well. Suppose that at Time 1 a consumer is making a decision that will harm herself at Time 2, with the long-run cost exceeding the short-term benefit. If the seller's incentives are aligned with the consumer's long-term interests, the seller will provide information or products intended to reduce or eliminate the internality. For obvious reasons, this is rarely the case. If fast food customers fail to take account of the health consequences of calories, for example, then fast food restaurants can exploit this failure by offering enticing but unhealthy menu options that are cheap to produce. Likewise, if car purchasers pay insufficient attention to fuel costs, then car manufacturers can offer gas guzzlers that are cheaper to produce and more attractive with respect to the attributes to which consumers attend.

Information disclosure can take a variety of forms (see, e.g., Teisl \& Roe, 1998; Worsfold \& Worsfold, 2007). The most appropriate form of disclosure depends on the situation in which a market failure arises. It is important to distinguish between situations in which information is verifiable (and misinformation can be punished) and those in which information is unverifiable. The calorie claims of a fast food restaurant and the fuel economy claims of an automobile manufacturer, for example, can be scientifically validated. However, if a doctor expresses the 
view that a patient is ideally suited for a clinical trial, there is no way to verify that he really believes that, or is conveying it because he will benefit by receiving a referral fee.

When information is verifiable, disclosure can focus on rectifying an information asymmetry - on providing information to the less informed buyer or advice recipient in order to level the informational playing field. When a drug company is required to include a warning label with a prescription drug, for example, the warning is designed to mitigate the asymmetry in information between the manufacturer of the drug, who has access to potential side effects, and the patient who, in the absence of the disclosure, would not. The same is true when an automobile company is required to include a label with the fuel economy of cars (Sunstein, 2013).

When information is unverifiable, however, mandatory disclosure attacking the information asymmetry would be useless because there would be no way to know if the disclosed information is accurate. ${ }^{1}$ In this case (as well as in the case of verifiable information), the informed party could still be required to disclose the misalignment of incentives. In New York State, for example, prospective home buyers and sellers are required to sign (to verify that they have been shown) a disclosure form designed to inform "potential buyers or sellers with whom [real estate licensees work] of their agency relationship and the rights and obligations it creates. This disclosure will help you to make informed choices about your relationship with the real estate broker and its sales agents.”

One might think it should be obvious to disclosees when interests are misaligned, so that no disclosure is necessary, but existing research suggests that many recipients of advice are not aware of misalignments, or at least behave as if they are not, taking advice from conflicted sources at face value (e.g., Malmendier \& Shanthikumar, 2007). Beyond suggesting to information recipients that they should perhaps mistrust information coming from advisors with misaligned incentives, awareness of the misalignment could also encourage advisees to seek out advisors with competing interests in order to hear both sides of an argument (Krishna \& Morgan, 2001). However, disclosure of the misaligned incentives could actually be harmful, too. People might overreact to disclosure, which might prevent an individual from getting good advice (see also Li \& Madarász, 2008, finding that this can occur even without overreaction), as would be the case if, for example, a sick patient avoided the doctor altogether upon learning of her conflict

\footnotetext{
${ }^{1}$ Even when information cannot be verified, some honest communication can occur (see Crawford \& Sobel, 1982; Farrell \& Rabin, 1996).
} 
of interest. In addition, when advisors are ethically motivated to provide unbiased advice, disclosure of misaligned incentives can potentially undermine this motivation (a phenomena of 'moral licensing' that is discussed in more detail in Section III).

Disclosures can also be delivered in various ways. In the case of a physician, for example, disclosure of a potential conflict of interest could come directly from the physician during the doctor-patient interaction, or could be provided in a less personal fashion (e.g., via printed information given to the patient by the receptionist in the waiting room). Disclosure can also be accompanied by greater or lesser efforts to ensure that consumers actually pay attention to it. For example, chain restaurants might be required merely to make nutritional information available to those who request it, or, as the Affordable Care Act mandates, to post the information on menu boards. From an economic perspective, some of these details might appear inconsequential, but in reality, as we will show, they can matter profoundly.

\section{Overview of the paper}

Although all three of the authors of this review are strong proponents of information disclosure and transparency (indeed, Sunstein worked to promote information disclosure in his capacity as Administrator of the White House Office of Information and Regulatory Affairs in the first term of the Obama Administration, and Loewenstein coauthored a dissent on a NAS report arguing in favor of broader disclosures of conflicts of interest (Bero, Krughoff \& Loewenstein, 2009)), we believe that important and reasonable questions have been raised about the efficacy of disclosure requirements. In this review, we try to provide a fresh perspective on the costs and benefits of mandatory disclosure, with an emphasis on psychological insights, and we use those insights to explore when disclosure is least and most likely to achieve its intended purposes, as well as how disclosure can be changed to enhance its efficacy.

In Section II, we provide a brief review of the standard (but surprisingly undeveloped) economic perspective on information disclosure. We show that the implications of economics for mandatory disclosure are highly dependent on special assumptions, and that some of those implications are surprising.

In Section III, we discuss several psychological phenomena that qualify the predictions and implications of the conventional economic analysis. Consistent with our title, we show that even a modest enrichment in our understanding of the psychology of the disclosers and/or recipients 
can have dramatic consequences for the types of effects we should expect to, and in fact do, observe, as well as profound implications for policy. For example, limited attention, motivated attention, and biased assessments of probability can undermine the goal of promoting informed consumer choice, potentially rendering disclosure ineffective. At the same time, disclosure requirements can have surprising large effects on providers as a result of what we call "the telltale heart effect.” In the domain of labor law, for example, one of the most significant applications of targeted transparency is OSHA’s Hazardous Communication Standard (HCS), which does not ban worker exposure to hazardous materials, but seeks "to ensure that the hazards of all chemicals produced or imported are evaluated, and that information concerning their hazards is transmitted to employers and employees.” As Estlund (2011:377) notes, "the HCS appears to have greater impact on employers' than on employees' decisions, and greater impact where there is a union that can interpret and act on the rather complex information involved” (we return to the important role played by intermediaries in Section IV). Similarly, whether disclosure of conflicts of interest by doctors, accountants, or investment professionals mitigates or exacerbates the problems caused by these conflicts may well depend less on the reactions of recipients than on the reactions of disclosers, who might respond by scaling back those conflicts or instead might, as a result of "moral licensing," feel freer to pursue their own interests at the expense of their clients.

In Section IV, we discuss the implications of research in psychology for when and how mandatory disclosure policies should be implemented to maximize benefits and minimize costs and unintended consequences. As we discuss, disclosure could be far more effective if it were simplified, standardized, or aided by intermediaries who could serve these functions. Section V offers a summary and directions for future research.

\section{The standard economic account of disclosure}

Economists tend not to address the benefits and costs of mandatory disclosure regulations head on, but focus instead on situations in which market failures may arise. Market failures can result from the absence of information, and hence potentially be rectified by its provision, when the social value of the information differs from its private value or when there are misaligned 
incentives between those with greater and lesser access to information (e.g., Akerlof, 1970; Ross, 1973).

We have already noted that information, as a public good, may have more social value than private value and hence be underprovided relative to the social optimum. When there are significant private costs associated with (acquiring or) disclosing information, but benefits are diffuse, no one has an incentive to procure or supply the information. In this case, mandatory disclosure may serve to promote the distribution of socially valuable information (Coffee, 1984).

Perhaps the paradigmatic situation in which asymmetric information and misaligned incentives can cause harm, and in which disclosure might seem likely to be helpful, arises in markets for consumer goods. Sellers and consumers clearly have different incentives: the seller is generally interested in making a profit by selling products that are cheap to produce at high prices, while consumers are interested in obtaining high quality products at low prices. Sellers, also, naturally, know more about the products they market than do consumers. Two problems can arise. First, due to the asymmetric information, consumers may be unable to identify, and hence purchase, the products that are best for them. An individual in the market for a credit card, for example, might be tempted by a "teaser rate," even if she would end up paying lower interest with a card that had a lower fixed rate. Second, due to the misaligned incentives, sellers may not produce high quality products (that could generate more consumer surplus) because, due to the asymmetric information, consumers would not reward them with purchases if they did. Sellers have an incentive to develop products that are strong in attributes that consumers can observe and weak in attributes to which they cannot or do not attend (Holmström, 1979). Mandatory disclosure of all relevant attributes would, in theory, address this problem. By reducing the information asymmetry between buyer and seller in this situation, mandatory disclosure could potentially align the seller's incentives with the consumer's (Mahoney, 1995), leading both to favor a product characterized by overall high quality. ${ }^{2}$

Although mandatory disclosure of information might be helpful in this situation, there are also reasons why it might be unnecessary (Easterbrook \& Fischel, 1984). First, one might expect market forces to lead to the voluntary provision of information, as firms compete with one another to advertise the strength of their own products to consumers, and the weakness of their

\footnotetext{
${ }^{2}$ There are, however, some obscure situations in which mandatory disclosure could worsen the problem of misaligned incentives (see Prat, 2005).
} 
competitors' products. For various reasons, however, competition may not be sufficient (Gabaix \& Laibson, 2006; Milgrom \& Roberts, 1986), perhaps because competitors’ interests might be more aligned with one another than with those of consumers, even in a highly competitive market (Heidhues, Koszegi \& Murooka, 2012). For example, a competitor selling a relatively safer product may prefer not to scare off consumers with a warning about more dangerous products in the marketplace.

A second reason why mandatory disclosure might not be necessary is that consumers’ skepticism could, in principle, force firms to disclose all information about their products, including adverse information. A sophisticated consumer, aware of the seller's incentives and ability to reveal information, can assume the worst about any information that is not revealed, which would force the seller to reveal everything (Milgrom, 1981; Grossman, 1981). ${ }^{3}$ In this case, it might be necessary only to disclose the misaligned incentives to consumers, so they can adopt the appropriate skeptical attitude. Of course, in order to use the strategy of skepticism, individuals must be aware of what information can be revealed, and, hence what information is not being revealed (Dye, 1985; Milgrom, 2008; Shin, 2003), and they must draw the logical conclusion that such missing information must be unfavorable (see also Fishman \& Hagerty, 2003). If consumers lack such awareness or fail to draw the logical conclusion (as discussed in the next section), then voluntary disclosure may not occur and mandatory full disclosure can once again be justified (Dranove \& Jin, 2010; Sunstein, 2014).

\section{Insights from Psychology}

In this section we discuss a series of psychological mechanisms that influence the judgments and behaviors of disclosers and disclosees. A pervasive theme is that disclosure may have little effect on recipients but large effects on providers.

\section{A note on evidence}

In light of the diversity of empirical research methods employed by psychologists and behavioral economists (who apply psychological insights to economic problems, typically using

${ }^{3}$ Consumer skepticism may not force sellers to voluntarily share their information if doing so would entail strategic costs (Board, 2009; Hotz \& Xiao, 2013). Mandatory disclosure would be warranted in these cases. 
economic methods), it will be useful to discuss some of the differences among different methodologies. The studies we review can roughly be classified on two dimensions, depicted in Table 1. Given that demand- and supply-side responses to disclosure often interact in subtle ways, studies in the right-hand column of the table - those that examine interactions between the demand and supply sides -- should probably be considered the 'gold standard' when it comes to understanding the impact of information disclosure regulations. Likewise, the quality of studies tends to improve as one moves toward the bottom rows of the table, given that studies involving real consequences for participants (and/or that are conducted in the field examining the behavior of the types of people who are actually likely to be affected by the regulations) tend to have greater external validity. By the same token, studies become more costly and difficult to conduct as one moves from the top left to the bottom right. We are, in fact, not aware of a single field experiment examining the interaction between the demand and supply side - i.e., a study that falls into cell XII. ${ }^{4}$

\footnotetext{
${ }^{4}$ There is an especially pressing need for more studies falling into the right-hand, and especially lower right-hand, column of table 1, because market-level interactions between the 'supply side' and the 'demand side' of disclosure can have important consequences, in some cases resulting in a redistribution of resources, or even undoing the benefits of disclosure. Suppose, for example, that a disclosure intervention drives many people who were previously choosing highly suboptimal, low-deductible health insurance plans toward more optimal high-deductible plans. If nothing else changes, consumers would all be better off than they would be without disclosure. But, due to competitive market forces, the lower health costs these individuals pay could be partly offset by higher premiums for everyone else, and those who had previously been making optimal choices with respect to premiums would see their aggregate health costs increase.

Disclosure, if effective in this situation, will not generate an aggregate benefit to consumers, but only a transfer of resources from the more sophisticated to the less sophisticated consumers.
} 
Table 1: Taxonomy of Information Disclosure Research Methodologies

\begin{tabular}{|l|c|c|c|}
\hline & \multicolumn{3}{|c|}{ Study Focus } \\
\hline \multicolumn{1}{|c|}{ Method } & $\begin{array}{c}\text { demand- } \\
\text { side }\end{array}$ & $\begin{array}{c}\text { demand } \\
\text { supply- } \\
\text { and } \\
\text { supply } \\
\text { side }\end{array}$ \\
\hline $\begin{array}{l}\text { hypothetical } \\
\text { choice }\end{array}$ & I & II & III \\
\hline $\begin{array}{l}\text { laboratory } \\
\text { experiments } \\
\text { with real } \\
\text { payoffs }\end{array}$ & IV & V & VI \\
\hline case studies & VII & VIII & IX \\
\hline $\begin{array}{l}\text { field } \\
\text { experiments }\end{array}$ & X & XI & XII \\
\hline
\end{tabular}

One other methodological point is worth making. Many of the studies reported in the literature fall into cell I of Table 1 - i.e., address hypothetical choices made by research subjects provided with information disclosure. Such studies are likely to overstate behavioral reactions to the disclosure, in part because it is easier to say that one will take some kind of protective action than actually to take it, and in part because the disclosures in such studies tend to be much more salient than they typically are in real world settings. The problem is compounded when subjects are given multiple decisions to make differing only (or mainly) on disclosures, because the variation of disclosures against an otherwise constant background will artificially increase their salience.

\section{Limited attention and awareness}

A growing body of research in economics (e.g., Sims, 2003) confirms what psychologists (e.g., Broadbent, 1958) have known and studied for decades: There are serious limitations on the amount of information to which people can attend at any point in time (see Simon, 1955 for an early treatment in economics). The standard economic account would emphasize that attention is a scarce resource and suggest that people make rational (even if fairly rapid) decisions about how to allocate it. Research in psychology, by contrast, suggests that people do not decide how to allocate attention; certain items capture attention while others disappear into the background, 
even if they are exceedingly important, and even if it would be rational to focus on them. The distinction between the two accounts matters for some purposes but not for others. The most general point is that limits on attention may well be the most important factor affecting the efficacy of disclosure.

Bounded attention renders many disclosures useless because consumers ignore them. ${ }^{5}$ They respond, “yeah, whatever,” and move on. For example, researchers (Carlos, Potts \& Jensen, 2005) find that fewer than $3 \%$ of consumers read the privacy disclosures that are so ubiquitous on websites, and that $75 \%$ of consumers think that the existence of a privacy policy implies privacy protection (Turow et al., 2008 ) even though the actual thrust of such policies is often the opposite - to secure the consumer's acquiescence in relinquishing privacy. ${ }^{6}$ Disclosures are so ubiquitous that we tend to be unaware of them, and, when the implicit is made explicit, one cannot help but be struck by the impossibility that anyone could attend to even a fraction of the disclosures to which we are exposed.

One of the most common, and obviously important, forms of disclosure involves product warning labels. Summarizing results from approximately 400 articles dealing with on-product warning labels, McCarthy et al. (1984) conclude that “on-product warnings have no measurable impact on user behavior and product safety.” When disclosure requirements turn out to be ineffective, it might be worthwhile to consider improved approaches that nonetheless involve information (see Section IV below) or other regulatory approaches, including default rules (Thaler \& Sunstein, 2008).

\section{Inattention to missing information}

As discussed in Section II, a key assumption of the economic analysis (leading to the conclusion that disclosure is unnecessary when disclosed information is verifiable) is that people are aware not only of information that they are presented but also of information they are not

\footnotetext{
${ }^{5}$ Other research shows that the impact of disclosures can be severely reduced by the introduction of even short delay, or distraction, between the delivery of a disclosure and a disclosure-relevant decision (Adjerid et al, 2013).

${ }^{6}$ This lack of attention, and resultant misconceptions, should come as no surprise. It has been estimated that $54 \%$ of privacy policies are beyond the grasp of $57 \%$ of the Internet population (Carlos \& Potts, 2004), and, somewhat amusingly, that the aggregate dollar value of the time it would take for US consumers actually to read privacy policies would be $\$ 652$ billion/year (McDonald \& Cranor, 2008).
} 
presented, but could be. More specifically, the standard economic analysis assumes that when companies provide individuals with selected information, people fill in the blanks with the worst possible values, assuming that if the information was favorable it would be disclosed. Research in psychology suggests that this key assumption is unlikely to be true. We have already discussed research showing that people have only limited capacity to attend to information that they are presented with; other research (summarized in Nisbett \& Ross, 1980) shows that people typically pay even less attention to the absence of information than to its presence, even when both are equally informative.

More evidence of inattention to missing information in a real world market context (Cell IX in Table 1) comes from research examining the cold-release of movies - i.e., the release to consumers without first giving access to reviewers. Studios cold-release movies when they are confident that the reviews will be unfavorable, and consumers should ideally draw the logical inference from the release of movies with no prior reviewer coverage. However, Brown, Camerer, and Lovallo (2012, 2013) find that, in fact, cold-released movies do initially better than movies that are pre-released to critics only to receive predominantly negative reviews.

The consequence of people's inattention to missing information is that voluntary disclosure policies are unlikely to be effective. If, for example, physicians could sign up for a clean conflict of interest certification, patients might infer from the lack of such a certification that a doctor must be conflicted. But if patients systematically fail to notice the absence of the certification, then doctors would be commensurately less motivated to eschew conflicts (Sah \& Loewenstein, 2013). Similarly, prior to the Nutritional Labeling and Education Act, makers of salad dressings with higher fat content chose not to label these products voluntarily, but with mandatory disclosure, their sales declined (Mathios, 2000).

\section{Motivated attention}

Even when people have the cognitive capacity to attend to the information provided by a disclosure, they do not always do so. Information is not only an input into decision making; it is a source of utility in its own right (e.g., Brunnermeier \& Parker, 2005; Caplin \& Leahy, 2001; Golman \& Loewenstein, 2013; Köszegi, 2010; Loewenstein, 1987; Schelling, 1987). When information is unpleasant to deal with, people often fail to attend to it. Research on investor logins, for example, shows that investors tend to log in and look up the value of their portfolio 
after a rise in the market, but 'put their head in the sand' after the market declines (Karlsson, Loewenstein \& Seppi, 2009; Sicherman et al., 2013). Research on medical testing for conditions, such as HIV, finds that the people who are most at risk often do not get tested because the prospect of the disease is too scary to think about, or because they are afraid to expose themselves to the risk of getting bad news (Thornton, 2008).

One such study examined the decisions of individuals at risk for Huntington's disease about whether to get tested (Oster, Shoulson \& Dorsey, 2013). Even though knowing whether one had the disease should be an enormously valuable input into decisions (such as whether to have children), many people chose not to get tested until they started experiencing symptoms. Even more interestingly, those who did not get tested made life decisions, such as whether to have children, that did not differ from those who were tested and discovered they did not have the disease; for purposes of decision making, people appeared to treat the absence of testing results as tantamount to the absence of the disease.

The most obvious implication of motivated attention for mandatory disclosure policies is that disturbing messages might well be ignored or downplayed. Research on the impact of emotional health warnings - so-called 'fear appeals' - does, in fact, show that scary warnings unaccompanied by immediate options for remediating action can backfire, apparently because people are deterred by fear from thinking about, and hence become less likely to respond to, the risks (Leventhal, 1971; Rogers, 1975; Loeber et al., 2011). In a similar phenomenon, people have been shown to suffer from unrealistic optimism, especially with respect to personal risks (Sharot, 2011), and unrealistic optimism could well weaken the effects of disclosure.

A more subtle implication is that disclosure policies intended to mitigate selective provision of information by firms may not work as well as might be expected. Even if companies do not engage in selective withholding of information (whether voluntarily or due to disclosure regulations), consumers may, in effect, take up the slack by paying attention to information that supports decisions that they may have already decided to make and ignoring or downplaying that which does not. If ice cream parlors would prefer not to post calorie information, but are forced to do so by regulations, consumers who like ice cream may take over the 'editing' role that regulations prevent the parlors from implementing, by ignoring information that, if attended to, would reduce their pleasure. 


\section{Biased probability judgments}

While standard economics allows for the idea that probability judgments might incorporate random error, the conventional assumption is that people do not display systematic biases - that, on average, people estimate things correctly. For a variety of reasons, this is not the case (see, e.g., Kahneman, Slovic \& Tversky, 1982). Research has found that people have systematically biased beliefs about, for example, food calorie content (Bollinger et al., 2010), returns to schooling (Jensen 2010), potential earnings in other countries (McKenzie et al., 2007), and the impact on energy consumption of driving cars differing in fuel economy (Allcott, 2011).

Misestimates of probabilities can have important implications for disclosure. For example, providing information about the health consequences of smoking is intended to deter people from smoking, and calorie information is intended to help people cut down on their calorie intake. But these effects are likely to occur only if, prior to disclosure, people are systematically biased in a direction that promotes the undesirable behavior, which may not be the case. Research by Viscusi (1990), for example (albeit controversial in part because he is a paid consultant to cigarette companies), finds that both smokers and nonsmokers tend to overestimate the health risks of smoking (though see Slovic, 2000, for a contrary perspective, finding underestimates of personal risk even in the face of accurate estimates or overestimates of statistical risks). If Viscusi is correct, then disclosure of the true risks of smoking could end up promoting smoking.

\section{Moral licensing}

There is by now a very large literature in behavioral and experimental economics demonstrating what people outside the profession might find obvious -- that people are powerfully driven by other-regarding motivations such as altruism, fairness, and a desire to perceive themselves as good people, and that, all else held equal, people prefer to tell the truth (Gneezy, 2005) and also expect others to do so (e.g., Valley et al., 2002). These motivations can be important in the types of misaligned relationships that are the common focus of disclosure policies, because they can motivate sellers to behave in the interests of buyers even when they have material incentives not to do so. ${ }^{7}$

\footnotetext{
${ }^{7}$ Cognitive biases can, in some situations, have a similar effect. The "curse of knowledge" (Camerer, Loewenstein \& Weber, 1989:1245) refers to the fact that people with private information often overestimate the extent to
} 
The fact that people are intrinsically motivated to provide unbiased advice and high quality products (even when they could pass off inferior ones to naïve consumers) is important, because disclosures of conflicts of interest can, in some cases, undermine such motivation, a phenomenon that Cain, Moore and Loewenstein (2005) dubbed 'moral licensing.' Moral licensing occurs when the perception that an advisee has been warned, via disclosure, of an advisor's potential bias makes the advisor feel less responsible for giving unbiased advice. In a study demonstrating the phenomenon, Cain, Loewenstein and Moore (2011) asked respondents to a survey to imagine that they were participating in an experiment in which they played the role of 'advisor' and gave advice to another person (the 'estimator') who would made money by accurately estimating how many jellybeans were in a jar that was depicted in a photo. Participants were all given a (hypothetical) conflict of interest: "Suppose that you are paid a $\$ 50$ bonus if the estimator overestimates the number of jellybeans in the jar." Participants were also told that the jar actually contained between 1900 and 2900 jellybeans. All participants were asked to rate the ethicality of suggesting "a number above 2900 (in hopes that the estimator overestimates the number of jellybeans)," but in one condition estimators were told that "the estimator is unaware of your $\$ 50$ incentive," and in the other they were told that "the estimator is aware of your \$50 incentive." Consistent with moral licensing, respondents reported that it would be more ethical to overstate the number when the estimator was aware of the conflict.

In a series of stylized experiments, the same authors showed that moral licensing was sufficiently strong so that conflicted advisors were better off, and advice recipients were worse off, when a conflict was disclosed, as compared to the same situation but without disclosure (Cain et al., 2005). These findings were later replicated and extended in an experiment modeling a real-life situation of a homebuyer and a conflicted real estate agent (Cain et al., 2011). These studies (falling into cell VI in table 1) show that, beyond the problem of information disclosure having little impact, disclosure of misaligned incentives can in some cases backfire, hurting those it is intended to help.

which it is shared. As the authors note, "By making better-informed agents think that their knowledge is shared by others, the curse helps alleviate the inefficiencies that result from information asymmetries, bringing outcomes closer to complete information (first-best) outcomes. In such settings, the curse on individuals may actually improve social welfare." 


\section{Panhandler and insinuation anxiety effects}

Two additional psychological phenomena raise further concerns about the potential for disclosure of misaligned incentives to backfire. Disclosing that an advisor has a conflict of interest does, research suggests, have the intended consequence of decreasing advisee trust. But perversely, due to two psychological mechanisms, it can also increase pressure to comply with the distrusted advice.

The first mechanism, the 'panhandler' effect, results from the fact that once a conflict has been disclosed, the advisor's interests become common knowledge, and, in some situations, advisees may feel pressured to help advisors obtain their personal interests. For example, once a doctor discloses that he or she earns a large referral fee if their patient enrolls in a clinical trial, the patient may implicitly feel that he or she is being asked to "help" the doctor get the fee.

Insinuation anxiety arises from the advisee's fear that rejecting advice (once they learn about a conflict of interest) sends a negative signal that they believe the advice is biased and the advisor is corrupt. Without disclosure, for example, an investor might not want to invest in a new mutual fund recommended by their financial advisor due to risk aversion or satisfaction with current investments. However, after the investment advisor has disclosed that he/she will receive a financial benefit if the investor buys into the new fund, the customer may fear that their failure to follow the advisor's recommendation to do so is likely to be interpreted as a signal of distrust - an indication that they doubt the advisor's ability to transcend the conflict.

In a pair of papers, Sah, Loewenstein and Cain (2012; 2013) report on the results of lab studies involving hypothetical and real outcomes, as well as field studies, in which conflicted advisors interacted with advisees who either were or were not informed of the conflict. In all experiments, disclosure increased distrust in advice but, due to either the panhandler effect or insinuation anxiety, also increased advisees' feelings of pressure to comply with it. Moreover, in several of the experiments, the latter influence was stronger than the former, so that advisees ended up being more likely to comply with the advice, even though they trusted it less.

\section{The spotlight and the 'telltale heart' effect}

Psychology does not always work against the effectiveness of disclosure. On the contrary, the 'telltale heart effect' suggests that psychological factors may increase the effectiveness of disclosure when, from an economic standpoint, it might be expected to be 
superfluous. In the classic account of how disclosure works (e.g., Fung, Graham \& Weil, 2007), mandated disclosure leads to changes in the behavior of disclosees, which in turn cause disclosers to 'clean up their act.' In a case often cited as a paradigm for successful disclosure, for example, hygiene ratings of restaurants in LA affected patronage patterns, which then motivated restaurants to improve their sanitation practices (see, e.g., Jin \& Leslie, 2003). ${ }^{8}$ But in many situations (to some extent including the case of restaurant hygiene ratings), an industry response can be found amidst little evidence of a consumer response.

This pattern raises an obvious question: Why are providers changing their products in response to disclosures that their customers are largely ignoring? On the basis of profit considerations alone, consumer inattention should lead producers to do exactly what they were doing before. Evidently some disclosers either have an exaggerated expectation of the likely consumer response or feel guilty about the information disclosed. We suspect that sellers may well have an inflated sense of the public salience of disclosures, in a phenomenon related to the spotlight effect (Gilovich et al, 2000), by which people exaggerate how much other people are looking at them, and also analogous to the confession of the protagonist in Edgar Allen Poe's (1843) famous short story, The Telltale Heart, who imagines that the police can hear the heartbeat of the man he has killed and buried beneath the floorboards of his apartment.

Most current evidence generally seems to suggest either a modest effect or no effect, on consumers, from calorie labeling (e.g., Harnack \& French, 2006). ${ }^{9}$ But in a study that provides evidence suggestive of a telltale heart effect, Namba et al. (2013) combed an archive of publicly accessible web pages for changes in posted menu offerings at fast food restaurants between 2005 and 2011, a period during which several municipalities introduced calorie posting. Menus from 5 fast-food chains with outlets in areas subject to menu-labeling laws were compared with menus from 4 chains operating in areas not requiring labeling. Although the overall prevalence of

\footnotetext{
8 The same authors also obtained evidence that mandatory disclosure was more effective than voluntary disclosure, and that, although the grade cards did lead to real improvements in hygiene, they also led inspectors to distort their ratings

${ }^{9}$ See, however, Bollinger et al. (2010) finding a nontrivial effect on consumer choices.
} 
healthier food options remained low over the period, restaurants located in areas that implemented calorie labeling increased healthier entrée options. ${ }^{10}$

Increasing the number of healthy options does not, however, mean that consumers will necessarily choose them. In a study showing that a greater prevalence of healthy options can end up backfiring by creating a 'halo effect,' Chandon et al. (2007) finds that consumers significantly underestimate the calories in an ostensibly "healthier" meal from Subway than for a comparable meal from McDonald's. The same study also finds that health claims can lead consumers to order sides and beverages that contain more calories, a kind of substitution effect also observed in a field experiment conducted at Subway, in which consumers were 'nudged' toward lower calorie entrees via a 'convenience menu' that included only low calorie sandwiches (Wisdom, Downs \& Loewenstein, 2009).

Further evidence suggestive of a telltale heart effect comes from the literature on appliance purchases, which to date provides relatively weak evidence of consumer responsiveness to energy efficiency labeling, but much stronger evidence of manufacturer responsiveness. Newell et al. (1999), for example, find that after energy efficiency labeling was mandated in the U.S., responsiveness of energy-efficient innovation in appliances to energy price changes increased substantially. Waide (2004) documents a trend toward more efficient products in the EU that began right after the onset of labeling and that was so strong that market saturation of certain appliances with an "A" rating led regulators in the EU to create A+ and A++ ratings to encourage greater efficiency through product differentiation.

One situation in which a telltale heart effect may be especially effective is corporate ethics and socially responsible behavior. Writing not only about corporations' concern for their public image, but also about consequent potential benefits of information disclosure regulations, Estlund (2011:378) contends that "the lengths to which leading firms go to advertise their virtuous performance on matters of sustainability, diversity, ethics, and overall social responsibility suggest that more is at work than ordinary labor market or product market competition... Mandatory disclosure of accurate information about socially salient conditions of employment (as well as other objects of CSR claims), would help to ensure that there is a factual

\footnotetext{
10 The average calorie content for entrée items showed no similar difference in changes across the two groups of restaurants (presumably because with calorie labeling, unhealthier options got even worse).
} 
basis for firms' claims of social responsibility, and that firms cannot easily buff up their reputation for good citizenship without improving their actual practices.” The telltale heart effect might well be playing a role here.

\section{Making disclosure work}

The research just reviewed has implications not only for when and why disclosure is likely to work or backfire, but also for potential improvements of disclosure policies.

\section{Simplification}

Given the limits of human attention, perhaps the most obvious way to improve the effectiveness of disclosures is to simplify them. As Ripken writes, "In order for a disclosure system to be effective, not only must the information that is supplied be disclosed completely, clearly, and accurately, but it must also be read and comprehended by the consumer. Here is where disclosure today fails in its purpose." Her paper focuses on financial disclosure, where the problem is especially acute since corporate disclosure documents tend to be packed with abstruse text written to protect companies from liability rather than to provide investors with comprehensible information. But the point is broadly applicable.

Barghava and Manoli (2013) provide evidence for the benefits of simplification. In a field experiment testing different interventions to increase take-up of the Earned Income Tax Credit (EITC) using mailed communications, they found that decreasing the complexity relative to a baseline notice (which itself produced take-up of 14\%) increased take-up by 6 percentage points. Also consistent with an important role for simplicity, increasing complexity decreased take-up by 4 percentage points.

If information simplification is, in principle, a good thing, exactly how to simplify information is anything but a simple problem, and again some obvious approaches may have unexpected pitfalls. Studies conducted both in the U.S. and abroad have shown that using categorical labels, such as stars or letter-grades, rather than a continuous scale, leads to better comprehension, a faster grasp of label information, and greater ease of use (Thorne \& Egan 2002; Wiel \& McMahon 2003). Newell and Siikamaki (2013), for example, found that consumers who were exposed to different energy efficiency disclosures and made hypothetical 
choices between water heaters (in a within-subjects experiment) were more responsive to, and more likely to make cost-efficient decisions after receiving, simple as compared with more complex energy efficiency labels. Consumers were most influenced by simple information about the monetary value of saving energy; additional information about placing this cost within a range of comparable models did not have significant additional value. Perhaps most importantly, a categorical label leads to increased self-stated motivation on the part of the consumer to consider energy efficiency as part of the purchase decision (Newell \& Siikamaki 2013; FTC 2006). ${ }^{11}$

On the other hand, results from two preliminary studies (VanEpps, Downs \& Loewenstein, in progress) point to the potential pitfalls of categorical ratings. While ordering lunch, subjects in both studies (one conducted at a fast-food restaurant and the other using a web-based ordering system at an office building) were presented with menus on which food items were designated by traffic lights that corresponded to their calorie content. Green light items had fewer calories than yellow and red light items. But in both studies, people seemed to take green as the "go" sign that it typically is, and they availed themselves more freely of green light items. Worse, when people did decide to select yellow or red light items, they tended to opt for higher calorie items within the category, seemingly with the logic that "if I'm going to consume a red light item anyway, I might as well get the most fulfilling one I can.”

If simplification is the general goal, perhaps the most obvious change in policy with respect to mandatory disclosure regulations is one that would be most difficult to implement: reduce the number of less important disclosures so as to increase the salience of the most important ones. In today's regulatory environment, the obstacle to such a change is that disclosure regulations arise from a wide range of legislative and regulatory sources at the federal, state and local levels.

\section{Standardized and comparative information}

People are generally able to make more coherent and rational decisions when they have comparative information that allows them to assess relevant tradeoffs (see, e.g., Hsee et al.,

${ }^{11}$ However, for $15 \%$ of the consumers in this study, the presence of CO2 information decreased willingness to pay for a lower operating cost. This surprising result may be a product to political reactions to 'environmental issues' and reflect how those reactions may negatively affect energy efficiency adoption (Gromet et al., 2013). 
1999). This point suggests that disclosures that provide comparisons, or information in standardized formats that facilitate comparisons, may have the greatest impact and benefit. If information is presented in a way that does not allow comparisons, it may not be meaningful, especially because people might not do the cognitive and other work that would enable them to make such comparisons on their own.

Energy efficiency labels for automobiles and appliances in the U.S. are only two examples of many disclosures that do provide comparative information - in such cases about how the operating costs of the car or appliance in question compare to that of others. Another example is the College Scorecard, which is intended to promote better post-secondary education choices. The Scorecard provides standardized information that allows prospective college students to compare costs, graduation rate, loan default rate, amount borrowed, and employment for every degree-granting institution in the country.

Although (and perhaps because) the benefits of providing standardized information about alternative products appear manifest, there is not a great deal of research that examines whether such information makes a difference. Some evidence does, however, suggest that comparative information along with other interventions can be effective. In one study (Bertrand \& Morse, 2011), prospective payday borrowers, already routinely provided with the APR of payday loans (typically around 450\%), were also provided comparative information about the cost of other types of loans. In one treatment, the typical APR of a payday loan was contrasted with that of other loans that consumers were likely to be familiar with such as car loans (typical APR 18\%), credit card (16\%) and subprime mortgage (10\%). In another treatment, the dollar cost of payday loans of durations ranging from 2 weeks to 3 months was contrasted against the much lower dollar costs of credit card debt. A third treatment provided information about the (high) fraction of people taking out payday loans who end up renewing the loan. The dollar cost information condition had the largest, although somewhat modest and only marginally significant, impact, both on loan initiation and loan amount. Since this was not the only comparative condition, but was the only condition involving dollar as opposed to percentage information, the former may have been the key aspect of the intervention that increased its impact. Indeed, another (albeit hypothetical choice) experiment, examining choice of investment funds differing in fees by financially illiterate workers (Hastings \& Tejeda-Ashton, 2008), also found a greater impact on choice of presenting information in dollar, rather than percentage point, terms. 
In a randomized field experiment, some senior citizens choosing between Medicare drug plans were randomly selected to receive a letter with personalized, standardized, comparative cost information (Kling et al. 2012). Plan switching was 28\% in the intervention group, but only $17 \%$ in the comparison group, and the intervention caused an average decline in predicted consumer cost of about $\$ 100$ a year among letter recipients. Note, however, that this intervention combined a number of different aspects (comparative and personalized information), so we cannot isolate a single mechanism that explains its effectiveness (a point we return to in the next subsection).

Other research suggests that merely providing comparative information is insufficient to enhance choice; it is important how information is sorted. In a study of the impact of the U.S. News and World Report college rankings, Luca and Smith (2013) exploited a natural experiment that resulted from a change in the way that universities were listed. From 1989-1994, the top 50 universities were listed with the top 25 universities in order of rank, but the next 25 ordered alphabetically (though reporting rank). In 1995, U.S. News began listing all of the top 50 universities in order of rank. The authors found that a change in rank for universities in the bottom half of the 1-50 range had a significant impact when all 50 were ordered by rank (high salience), but no impact when the focal universities were ordered alphabetically (even though rank was reported). ${ }^{12}$ The evident reason is that with the alphabetical listing, some cognitive work had to be done to ascertain ranking, and even though that work was modest, people declined to do it.

A different study examined the impact of simplified school-level academic performance information on the school choices of parents in the Charlotte-Mecklenburg Public School District (Hastings \& Weinstein, 2008). The study produced less encouraging results, both for simplification and ordering. In a randomized field experiment (one of two studies that the authors report), parents of children in randomly selected schools who were provided with

\footnotetext{
${ }^{12}$ Similarly, Pope (2009) finds that changes in the ranking of hospitals (and specialties within hospitals) have a major impact on patient volume, even though the continuous score on which the rankings are based (which is arguably a finer-grained measure of the same thing) has no significant additional impact.
} 
statistics on, and sorted by, different schools' academic achievements, did not make better school choices than those who did not receive the information. ${ }^{13}$

\section{Social comparison information}

Media mogul Ted Turner once complained that Forbes Magazine published a list of the wealthiest Americans but not the most generous, an omission that was later corrected by Slate Magazine. Research suggests that such social competition can encourage generosity. ${ }^{14}$ Social comparison information can operate through a variety of channels. Beyond playing on the natural human desire to be above average on almost anything that can be measured, social comparison information can potentially establish ‘descriptive norms’ that often convert into ‘injunctive’ ones (Schultz et al. 2007).

Perhaps the most carefully studied intervention provides homeowners with information about how their energy use compares with that of their neighbors. Opower, a company based in Virginia, works with utilities to send people a personalized Home Energy Report, which includes comparison to their neighbors (for example "great," "good,” and “more than average”) and is accompanied by “Energy Saving Tips,” such as “move your thermometer up 2 degrees,” and “when you're away, set it higher.” Evaluations of the Opower intervention have found that when people learn that they are using more energy than similarly situated others and are provided with tips on how to reduce energy use, their energy use declines significantly (Allcott \& Rogers, 2012; Allcott, 2011). Although the effects are not large (approximately a $2 \%$ reduction), the cost-effectiveness of the intervention compares favorably to that of other, more standard programs designed to promote energy conservation.

It is important to emphasize, however, that the causal mechanisms are not yet well identified, because the program combines comparative information with tips (sometimes described as "channel factors" in the psychological literature), and existing designs cannot

\footnotetext{
${ }^{13}$ The natural experiment did, however, provide support for the idea that mailing parents (albeit somewhat complicated) information about school performance did improve their school choice decisions.

${ }^{14}$ In a clever experiment, Duffy and Kornienko (2010) found that subjects who played a sequential "dictator game" gave more when placed in a generosity tournament (in which subjects were publically ranked from most to least generous) as compared with an 'earnings' tournament in which subjects were ranked according to how much they kept, even though there was no award associated with winning the tournament.
} 
exclude the possibility that the effects result from an increase in energy awareness on the part of the consumer as a consequence of receiving the report, regardless of its specific content (see Schwartz et al., in press). It should also be noted, that several studies have found little or no impact of social comparison information, and at least one study (the previously discussed study by Barghava and Manoli, 2013) actually found that social comparison information had a perverse effect, decreasing takeup of the EITC by $4.4 \%$.

Public ratings of corporations and other institutions have also been found to influence their behavior. One paper, for example, examined the impact on firm behavior (release of toxic chemicals, as reported to the U.S. Environmental Protection Agency's Toxic Release Inventory) of being suddenly included among the ranks of firms whose relative performance was publicly graded (Chatterji \& Toffel, 2010). The researchers found that firms that initially rated poorly subsequently improved their performance, as compared to firms that were never rated or rated more favorably. Other studies of the same program also find significant effects, which they attribute to a fear of “environmental blacklisting” (Fung \& O’Rourke, 2000; Hamilton, 2005; Konar \& Cohen, 1997).

Social comparison information also seems to have played a role in positive progress made in reducing certain types of conflicts of interests in academic medical centers (those associated with gifts to physicians from pharmaceutical companies and device manufacturers). The American Medical Student Association PharmFree Scorecards (which grades COI policies at US academic medical centers; see www.amsascorecard.org) appears to have been successful in encouraging many academic medical centers to implement stronger COI policies. Similarly, mandatory disclosure of marketing costs for prescription drugs in the District of Columbia produced a downward trend in marketing expenditures by pharmaceutical companies, including gifts to physicians, from 2007 to 2010, and the announcement of the names and amounts received from industry by the top eight physician speakers in 2009 resulted in a significant drop in the amounts received by this group in the subsequent year compared to a comparison group (the next eight speakers whose names and industry amounts were not disclosed) (The George Washington University School of Public Health and Health Services, 2012).

Although these and many other examples suggest that "regulation by shaming" can be an effective strategy for improving the performance of firms and other organizations (Graham, 2000), it is important to note that in some situations, it can produce perverse effects. Rankings of 
schools by the media can produce a kind of self-reinforcing dynamic whereby low ratings lead to a drying up of resources and decline in the quality of students, making it difficult if not impossible for schools to rectify problems identified by their rankings (Espeland \& Sauder, 2007).

Moreover, social comparison information does not even always lead to a desire to improve, at least on the intended dimension. In the case of Opower, providing the social comparison information does seem to lead to an average net decrease in electricity usage, but some studies have documented so-called "boomerang effects" whereby those discovering that they are consuming less than average actually increase their usage (Schultz et al., 2007; see also Costa \& Kahn, 2013, finding that Republicans increased their energy usage; but see Allcott, 2011, finding no such effect).

\section{Vividness}

It is well-understood that vivid displays may have a larger impact than dry, statistical information (see, e.g., Nisbett \& Ross, 1980), and this point has significant lessons for disclosure policies. In the context of smoking, for example, many studies indicate that warnings that combine pictures and text are more effective than text alone in decreasing demand for cigarettes - perhaps by triggering strong emotions, perhaps by increasing awareness of risks, and perhaps by promoting thoughts about quitting. (See Borland et al., 2009; Hammond et al., 2006; O’Hegarty et al., 2006; Thrasher et al., 2011). In that context, the relevant pictures can be gruesome or shocking, such as images of diseased organs, and these images have been found to have a greater impact on smokers than words suggesting more abstract injury (Sobani et al, 2010). As discussed in section III (under the heading of motivated attention), however, there is some danger that the use of pictorial warnings could backfire; consumers might direct their attention away from the gruesome pictures, and thus insulate themselves from the warning information (e.g., Loeber et al., 2011).

\section{Smart disclosure and the role of intermediaries}

In some situations, exemplified by the abstruse legalistic disclosures accompanying securities transactions, the language or underlying information is far too complex for a layperson to digest. In other situations, exemplified by the privacy notifications that no one reads on 
Internet sites, the volume of information is overwhelming and not worth the investment one must make to read it. In still other situations, exemplified by conflict of interest disclosures, the disclosures are neither complicated nor long, but their implications for behavior are difficult to assess. If a doctor informs a patient that she will receive a referral fee if the patient enters a clinical trial she recommends, should the patient decline to enroll? Making this determination requires a difficult judgment about whether the doctor's recommendation has been colored by the disclosed conflicts.

In all of these situations, unsophisticated recipients of advice could likely benefit from the intervention of more savvy intermediaries to help them make sense of the information. Many non-profit organizations, such as the Consumer's Checkbook (http://www.checkbook.org/), already perform this function. Instead of attempting to provide information directly to consumers, disclosure requirements could make information available in standardized formats so that intermediaries can arise to process it, make sense of it, and (perhaps for a fee) provide it in a form that is usable to its end users. Such an approach might well yield benefits beyond those contemplated by its implementers. Consider GPS information, which is used in creative and useful ways that early proponents of its release could never have anticipated. Consistent with this goal, the "Smart Disclosure” initiative, undertaken by the Obama Administration (Sunstein, 2013), is designed to encourage providers to disclose downloadable, machine-readable information, in part so that intermediaries can help consumers of (for example) energy and health care to learn about their own behavior and, as a result, make more informed choices.

\section{Promise and pitfalls of in-person disclosures}

Given that many disclosures have little impact because they fail to stand out among the onslaught of competing disclosures, it is reasonable to expect that in-person disclosure would be a good thing, in part because it might increase salience. There is, however, very little evidence to support (or refute) this prediction. One field experiment conducted by Chetty and Saez (2013) found no impact on earnings in the year following a two-minute tutorial on the financial consequences of the Earned Income Tax Credit delivered in-person by tax preparers to lowincome clients. However, the lack of response may well have reflected the complexity of the incentives and subtlety of behavioral adjustments that individuals would have had to make to respond to incentives. 
Although in-person disclosure might well increase salience, it also has demonstrated pitfalls. In a series of follow-up experiments to the studies by Sah, Loewenstein, and Cain (2012, 2013) described earlier, the authors tested different remedies for the adverse effects of insinuation anxiety and the panhandler effect. These studies revealed that advisees who received the COI disclosure from an external source (i.e., not directly from the individual with the conflict), who could make their choices privately, or who could change their minds afterwards were less likely to follow biased advice than those who were informed of the COI by the advisor and had to make their final choice in her presence. These results suggest the possibility that people should not make significant decisions until they have had time to think on their own (away from their advisors) or unless a cooling-off period is available in which clients have the opportunity to cancel or change their minds without consequence. Applied to medicine, for example, the research points to the prescription for policy that patients should decide whether to follow recommended treatments only after leaving the pressures of the doctor's office.

\section{Disclosure versus other policies}

As we have shown, disclosure holds considerable promise as a tool of public policy, especially as a means of altering the behavior of disclosers as opposed to disclosees. However, it also has severe limitations, and can backfire in certain situations, damaging the interests of those it is intended to help. Given these limitations, and the always present temptation of taking the path of least resistance, policy makers need to be vigilant against the risk that mandatory information disclosure policies will be implemented as a substitute for other, often more effective, regulatory interventions (see Loewenstein \& Ubel, 2011).

\section{Further Directions and Conclusions}

\section{Other domains of disclosure}

Although we chose to restrict our review to a relatively narrow range of situations specifically interactions between buyers and sellers characterized by asymmetric information and misaligned incentives -- disclosure is an enormous topic, and could potentially encompass a very wide range of phenomena. For example, there is a burgeoning literature on the economics (and behavioral economics) of privacy (Acquisti \& Taylor, forthcoming) which looks at the issue of 
information disclosure from a very different perspective - that of individuals disclosing information to others, for example on social media. Although different in its focus, this research has also highlighted the importance of psychology by demonstrating a range of psychological mechanisms that lead people to divulge information when it is not in their interest to do so, but to 'clam up' when costs to disclosure are low or benefits are high (e.g., Acquisti, John \& Loewenstein, forthcoming).

Perhaps the most closely related, and in-depth, research that we do not discuss in this review is reported in the large literature dealing with transparency and accountability initiatives applied to (and coming from) government. In the U.S., statutes originating in the 1966 Freedom of Information Act and extending to the Obama Administration's “open-government” initiative, largely oriented to making the data routinely collected by the Federal Government easier to access and parse, have been discussed at some length (Sunstein, 2013), as have similar initiatives in countries as diverse as the U.K., Mexico, India and China (e.g., McGee \& Gaventa, 2011). Funding to study such initiatives, provided by several foundations, has resulted in a wide range of findings and insights, many parallel to those reported in this paper. For example, one of the important claims from the literature on open government initiatives is that transparency alone may not be sufficient to produce beneficial social change; for change to occur, it has been suggested that transparency has to be accompanied by accountability. Information provision may have little impact in the absence of institutions and mechanisms that have the capacity to channel the information into concrete action (see, e.g., Fox, 2007).

\section{Need for further research}

Although calls for further research in academic reviews are almost pro forma, the need for further research on the effects of disclosure requirements is evident from both the ubiquity of such requirements and the paucity of research that seeks to understand when, why and how they work. ${ }^{15}$ There is, first of all, a need for qualitative research examining how individuals and firms

\footnotetext{
${ }^{15}$ There is, for example, little evidence about the impact of personalizing information. Kling (2012) and Bettinger et al. (2012) have studied treatments involving personalized information along with other interventions, but the independent effect of personalization remains an open question.
} 
respond, or fail to respond, to disclosure. Regulators may fail to appreciate the nature and the extent of differences between their own goals and values and those of the people who are most affected by the disclosures. For example, proponents of calorie posting hold an implicit assumption, which is that the people whose health would benefit from calorie reduction will want to cut calories. This assumption undoubtedly holds for many of the recipients of the information, but for many others it may be an example of projection bias - of the tendency to assume that other people's goals are similar to one's own.

People who are overweight are disproportionately poor, and many poor people are as likely to want to save money as to lose weight. One way to save money is to maximize the 'bang for the buck' - i.e., calories per dollar - which the calorie information, combined with price information, can help a fast-food patron to do, potentially leading to a consequence opposite of the intended one. Although quantitative researchers rarely do more than pay lip-service to the benefits of qualitative research, disclosure regulation is a domain in which the need for qualitative research is especially pressing. The implementation and use by end-users of disclosures can bear little resemblance to what the originators had in mind.

The second pressing need is for additional randomized controlled trials and field experiments. Sometimes public policies get ahead of the data justifying their implementation. In light of the complex economic and psychological mechanisms at play in the real world, one of the major themes of this paper is the difficulty of anticipating demand and supply side reactions to disclosure requirements. This is precisely why experimentation is so important. Ideally, new proposed disclosures should be tested on a limited scale, via randomized field experiments, before they are rolled out to the general public (Greenstone, 2009).

Such limited-scale experiments should allow for more in-depth analyses of effects than have generally been conducted. For example, studies that have examined the impact of calorie labeling have tended to focus on the impact of labeling on a single meal. However, even if calorie labeling does change people's selections at a restaurant, any benefit could easily be undone if after eating a low-calorie lunch, people end up snacking more later in the day. In a study that examined the impact of 'nudges' and nutrition information on meal choice, for example, the calorie reduction benefits of a nudge toward lower-calorie sandwiches were undone because those so nudged were more likely to choose high-calorie side orders and drinks (Wisdom, Downs \& Loewenstein, 2009). 
Another way in which smaller scale experimental studies could go more in-depth would be to follow consumers over time to distinguish between short-term and long-term effects. On the one hand, one might expect effects to persist in the long-term if short-term changes result in changed habits, or if the information is learned and the learning results in sustained behavior change. In fact some studies do find such effects (e.g., Allcott \& Rogers, 2012). However, there is a risk that information disclosures will tend to lose impact over time as the information enters into the background of the consumer's awareness and ultimately becomes ignored.

\section{Conclusions}

Psychological factors severely complicate the standard arguments for the efficacy of disclosure requirements. Because attention is both limited and motivated, disclosures may be ignored, especially if they are complex, and new disclosures, even of valid information, may turn out to distract attention from older and possibly more important ones. As a result of limited attention and many other psychological factors discussed in Section III, disclosure requirements appear to have been less effective in changing recipient behavior than their most ardent proponents seem to assume they are, or should be.

At the same time, disclosure may have large effects on producers, which presents an independent puzzle: If consumers are unaffected by disclosure requirements, why would producers change their behavior? We have suggested that 'the telltale heart effect' provides a large part of the answer. Providers of information may well overestimate the likely effect of the disclosure on consumers, partly because that disclosure seems so salient to providers. As a result of the telltale heart effect information disclosure can have beneficial effects even when it fails to change consumer behavior.

Unfortunately, disclosure of misaligned incentives can have perverse effects on the producer side of the equation. Specifically, advisors who would have otherwise been intrinsically motivated to provide unbiased advice can feel 'morally licensed' to provide biased advice once a conflict of interest has been disclosed. Moreover, due to panhandler and insinuation anxiety effects, advice recipients may feel greater pressure, following disclosure, to follow the now less trusted advice.

We have suggested a set of psychologically informed strategies that might make disclosure more effective, including simplification, standardization, and the use of social 
comparisons. Clearly, further research is needed to gain a better understanding of when, why, and how disclosure policies have intended or unintended consequences, as well as how such policies can be improved, but one thing is clear: Psychology changes everything. 


\section{References}

Acquisti A, John L, Loewenstein G. Forthcoming. What is privacy worth? J. Legal Studies

Acquisti A, Taylor C. Forthcoming. The economics of privacy. J. of Econ. Lit.

Adjerid I, Acquisti A, Brandimarte, L, Loewenstein G. 2013. Sleights of privacy: Framing, disclosures, and the limits of transparency. Proceedings of the Symposium on Usable Privacy and Security (SOUPS) 2013.

Akerlof GA. 1970. The market for "lemons": Quality uncertainty and the market mechanism. The QJE 84(3): 488-500

Allcott H. 2011. Social norms and energy conservation. J. Public Econ. 95(9): 1082-95

Allcott H, Rogers T. 2012. The Short-Run and Long-Run Effects of Behavioral Interventions: Experimental Evidence from Energy Conservation. Work. Pap., NBER 18492

Bebchuk L., Jackson Jr. RJ. 2013. Shining light on corporate political spending. Georgetown Law J. 101(4): 923-67.

Bhargava S, Manoli D. 2013. Why are Benefits Left on the Table? Assessing the Role of Information, Complexity, and Stigma on Take-up with an IRS Field Experiment. Amer. Econ. Rev. In press

Ben-Shahar O, Schneider C. 2010. The failure of mandated disclosure. John Mi. Olin Law \& Economic Working Paper, No. 516, The Law School, University of Chicago, Chicago, IL

Bero L, Krughoff R, Loewenstein G. 2009. Appendix F: Model for broader disclosure. In Conflict of interest in medical research, education, and practice, ed B Lo, MJ Field, pp. 325-330. Washington, DC: The National Academies Press

Bertrand M, Morse A. (2011). Information disclosure, cognitive biases, and payday borrowing. J. Finance. 66(6): 1865-1893

Bettinger EP, Long BT, Oreopoulos P, Sanbonmatsu L. 2012. The role of application assistance and information in college decisions: results from the H\&R BLOCK FAFSA experiment The Quarterly J. of Econ. 127(3): 1205-1242

Board O. 2009. Competition and disclosure. J. of Indus. Econ. 57(1): 197-213

Bollinger B, Leslie P, Sorensen A. 2010. Calorie posting in chain restaurants. National Bureau of Economic Research, No. w15648 
Borland R, Wilson N, Fong GT, Hammond D, Cummings KM, et al. 2009. Impact of graphic and text warnings on cigarette packs: findings from four countries over five years. Tobacco Control 18(5): 358-64

Broadbent DE. 1958. The general nature of vigilance. Perception and Communication 340:108139.

Brown AL, Camerer CF, Lovallo D. 2012. To review or not to review? Limited strategic thinking at the movie box office. Am. Econ. J. Microecon. 4(2): 1-26

Brown AL, Camerer CF, \& Lovallo D. 2013. Estimating structural models of equilibrium and cognitive hierarchy thinking in the field: The case of withheld movie critic reviews. Mgmt. Sci. 59(3): 733-47

Brunnermeier MK, Parker JA. 2005. Optimal expectations. Am. Econ. Rev. 95(4): 1092-1118.

Cain D, Loewenstein G, Moore D. 2005. The dirt on coming clean: Perverse effects of disclosing conflicts of interest. J. Legal Stud. 34(1): 1-25

Cain D, Loewenstein G, Moore D. 2011. When sunlight fails to disinfect: Understanding the perverse effects of disclosing conflicts of interest. J. Consum Res. 37: 836-57

Camerer C, Issacharoff S, Loewenstein G, O’Donoghue T, Rabin M. 2003. Regulation for conservatives: Behavioral economics and the case for "asymmetric paternalism.” University of Pennsylvania L. Rev. 1151: 1211-1254

Camerer C, Loewenstein G, Weber M. 1989. The curse of knowledge in economic settings: An experimental analysis. J. of Political Econ. 97: 1232-1254.

Caplin A, Leahy J. 2001. Psychological expected utility theory and anticipatory feelings. QJE. 116(1): 55-79

Chandon P, Wansink B. 2007. The biasing health halos of fast-food restaurant health claims: Lower calorie estimates and higher side-dish consumption intentions." J. Consumer Res. 34(3): 301-314

Chatterji AK, Toffel MW. 2010. How firms respond to being rated. Strategic Mgmt. 31(9): 917945

Chetty R, Saez E. 2013. Teaching the tax code: Earnings responses to an experiment with EITC recipients. Am. Econ. J. Applied Econ. 5(1): 1-31

Coffee JC Jr. 1984. Market failure and the economic case for a mandatory disclosure system. Virginia L. Rev. 70(4): 717-753 
Costa DL, Kahn ME. 2013. Energy conservation “nudges” and environmentalist ideology: evidence from a randomized residential electricity field experiment. J. European Econ. Association 11(3), 680-702.

Crawford VP, Sobel J. 1982. Strategic information transmission. Econometrica 50(6): 1431-51

Dranove D, Jin GZ. 2010. Quality disclosure and certification: Theory and practice. J of Econ. Lit. 48(4): 935-963

Duffy J, Kornienko T. 2010. Does Competition Affect Giving? Journal of Economic Behavior and Organization 74(1-2): 82-103.

Dye RA. 1985. Disclosure of nonproprietary information. J. Accounting Res. 23(1): 123-45.

Easterbrook FH, Fischel DR. 1984. Mandatory disclosure and the protection of investors. Virginia L. Rev. 70(4): 669-715.

Estlund C. 2011. Just the Facts: The Case for Workplace Transparency. Stanford L. Rev. 63: 351407

Espeland WN, Sauder M. 2007. Rankings and reactivity: how public measures recreate social worlds. Amer. J. Socio. 113(1): 1-40.

Farrell J, Rabin M. 1996. Cheap talk. J Econ Perspective. 10(3): 103-118.

Fishman MJ, Hagerty KM. 2003. Mandatory Versus Voluntary Disclosure in Markets with Informed and Uninformed Customers. Journal of Law, Economics, and Organization 19 (1), 45-63.

Fox J. 2007. The uncertain relationship between transparency and accountability. Development in Practice 17(4-5): 663-671.

Federal Trade Commission (FTC). 2006. Appliance energy labeling consumer research background information for the notice of proposed rulemaking related to the effectiveness of the appliance labeling rule (16 C.F.R. Part 305)

Fung A, Graham M, Weil D. 2007. Full Disclosure: The Perils and Promise of Transparency New York: Cambridge Univ. Press

Fung A, Graham M, Weil D. 2013. Targeting Transparency. Science 340(6139): 1410-1411

Fung A, O'Rourke D. 2000. Reinventing environmental regulation from the grassroots up. Env. Mgmt. 25(2): 115-127

Gabaix X, Laibson D. 2006. Shrouded attributes, consumer myopia, and information suppression in competitive markets. QJE. 121(2): 505-540 
The George Washington University School of Public Health and Health Services. 2012. Pharmaceutical Marketing Expenditures in the District of Columbia, 2010. Washington, DC. http://doh.dc.gov/sites/default/files/dc/sites/doh/publication/attachments/pharmaceutical_ marketing_expenditures_in_the_district_of_columbia_2010.pdf

Gilovich T, Medvec VH, Savitsky K. 2000. The spotlight effect in social judgement: An egocentric bias in estimates of the salience of one's own actions and appearance. $J$ Personality and Soc. Psych. 78(2): 211-222

Golman R, Loewenstein G. Curiosity, Information Gaps, and the Utility of Knowledge. 2013 Available at SSRN: http://ssrn.com/abstract $=2149362$ or http://dx.doi.org/10.2139/ssrn.2149362

Gneezy U. 2005. Deception: The role of consequences. Amer. Econ. Rev. 95(1): 384-94

Graham M. 2000. Regulation by shaming, Atlantic Monthly. April: 36-39

Greenstone M. 2009. Toward a Culture of Persistent Regulatory Experimentation and Evaluation. In New Perspectives on Regulation ed. D Moss, J Cisternino, 111

Gromet DM, Kunreuther H, Larrick RP. 2013. Political ideology affects energy-efficiency attitudes and choices. Proceedings of the National Academy of Sciences 110(23): 9314-19

Grossman S. 1981. The Informational Role of Warranties and Private Disclosure About Product Quality. J of Law and Econ. 24(3): 461-483

Gruber J, Koszegi B. 2001. Is Addiction Rational? Theory and Evidence. Quarterly J. of Econ. 116(4): 1261-1305

Hamilton J. 2005. Regulation through revelation. New York, NY Cambridge University Press

Hammond D, Fong GT, McNeill A, Borland R, Cummings KM. 2006. Effectiveness of cigarette warning labels in informing smokers about the risks of smoking: findings from the International Tobacco Control (ITC) Four Country Survey. Tobacco Control 15(3): iii19iii25

Hastings JS, Teja-Ashton L. 2008. Financial literacy, information, and demand elasticity: survey and experimental evidence from Mexico. Work. Pap., NBER 14538

Hastings JS, Weinstein JM. 2008. Information, school choice, and academic achievement: evidence from two experiments. Quarterly J. of Econ. 123(4): 1373-1414

Heidhues P, Koszegi B, Murooka T. 2013. The Market for Deceptive Products. Work. Pap., Univ. of California, Berkeley 
Herrnstein R, Loewenstein G, Prelec D, Vaughan W. 1993. Utility maximization and melioration: Internalitites in individual choice. J Beh. Dec. Making 6:149-185

Hölmstrom B. 1979. Moral hazard and observability. The Bell Journal of Economics, 74-91.

Hotz VJ, Xiao M. 2013. Strategic information disclosure: The case of multiattribute products with heterogeneous consumers. Economic Inquiry. Volume 51, Issue 1, pages 865-881.

Hsee CK, Loewenstein GF, Blount S, Bazerman MH. 1999. Preference reversals between joint and separate evaluations of options: A review and theoretical analysis. Psych. Bulletin, 125(5): 576-90

Jensen C, Potts C. 2004. Privacy policies as decision-making tools: an evaluation of online privacy notices. Proceedings of the SIGCHI conference on Human factors in computing systems. ACM

Jensen C, Potts C, Jensen C. 2005. Privacy practices of Internet users: self-reports versus observed behavior. Intl. J. of Human-Computer Stud. 63(1): 203-227

Jensen R. 2010. The (perceived) returns to education and the demand for schooling. QJE 125(2): 515-548

Jin GZ, Leslie P. 2003. The effect of information on product quality: Evidence from restaurant hygiene grade cards. QJE 118(2): 409-451

Jovanovic B. 1982. Truthful disclosure of information. Bell J. of Econ. 13(1): 36-44

Kahneman D, Slovic P, Tversky A. 1982. Judgment under uncertainty: Heuristics and biases. Cambridge, England: Cambridge Univ. Press

Karlsson N, Loewenstein G, Seppi D. 2009. The ostrich effect: Selective avoidance of information. J. of Risk and Uncertainty 38(2): 95-115

Kling JR, Mullainathan S, Shafir E, Vermeulen LC, Wrobel MV. 2012. Comparison friction: Experimental evidence from Medicare drug plans. QJE. 127(1): 199-235

Kleindorfer PR, Orts EW. 1998. Informational regulation of environmental risk. Risk Analysis. 18(2): $155-170$

Krishna V, Morgan J. 2001. A model of expertise. QJE 116(2): 747-775

Lansky D. 2002. Improving quality through public disclosure of performance information. Health Affairs 21(4): 52-62

Leventhal H. 1971. Fear appeals and persuasion: The differentiation of a motivational construct. Am. J. Pub. Health 61: 1208-1224 
Li M, Madarász K. 2008. When mandatory disclosure hurts: Expert advice and conflicting interests. J. Econ. Theory 139(1): 47-74.

Loeber S, Vollstadt-Klein S, Wilden S, Schneider S, Rockenbach C. 2011. The effect of pictorial warnings on cigarette packages on attentional bias of smokers." Pharmacology Biochemistry and Behavior 98(2): 292-98

Loewenstein G. 1987. Anticipation and the valuation of delayed consumption. The Econ. J. 97(387): 666-684

Loewenstein G, O'Donoghue T. 2006. "We can do this the easy way or the hard way": Negative emotions, self-regulation and the law. University of Chicago L. Rev. 73(1): 183-206.

Loewenstein G, Ubel P. 2010. Economics Behaving Badly. New York Times, Jul. 14, p. A31

Luca M, Smith J. 2013. Salience in quality disclosure: evidence from the U.S. News college rankings. Journal of Economics and Management Strategy 22(1):58-77.

Mahoney PG. 1995. Mandatory disclosure as a solution to agency problems. Univ. Chicago L. Rev. 62(3): 1047-1112

Malmendier U, Shanthikumar D. 2007. Are small investors naïve about incentives? J. Financial Econ. 85(2): 457-89

McCarthy RL, Finnegan JP, Krumm-Scott S, McCarthy GE. 1984. Product information presentation, user behavior, and safety. Proceedings of the Human Factors and Ergonomics Society Annual Meeting 28(1): 81-85

McDonald A, Cranor F. 2008. Cost of reading privacy policies. I/S: A Journal of Law and Policy for the Information Society 4: 543

McGee R, Gaventa J. 2011. Synthesis report: Review of impact and effectiveness of transparency and accountability initiatives. Transparency and Accountability Initiative. http://www.transparency-initiative.org/wpcontent/uploads/2011/05/synthesis_report_final1.pdf

Milgrom PR. 1981. Good news and bad news: Representation theorems and applications. The Bell J. 12(2): 380-91

Milgrom PR. 2008. What the seller won't tell you: Persuasion and disclosure in markets. The $J$. of Econ. Perspectives, 22(2): 115-132.

Milgrom PR, Roberts J. 1986. Price and advertising signals of product quality. The J. of Pol. Econ. 94(4): 796-821 
Namba A, Aucincloss A, Leonberg BL, Wootan MG. 2013. Exploratory analysis of fast-food chain restaurant menus before and after implementation of local calorie-labeling policies, 2005-2011. Prev. Chronic Dis. 10:120224

Newell RG, Jaffe AB, Stavins RN. 1999. The induced innovation hypothesis and energy-saving technological change. QJE 114(3) 941-975

Newell RG, Siikamäki J. 2013. Nudging energy efficiency behavior. Work. Pap., NBER 19224

Nisbett RE, Ross L. 1980. Human inference: strategies and shortcomings of social judgment. Englewood Cliffs, N.J.: Prentice-Hall.

O'Dougherty M, Harnack LJ, French SA, Story M, Oakes JM, Jeffery RW. 2006. Nutrition labeling and value size pricing at fast food restaurants: a consumer perspective. Am. J. of Health Promotion 20(4): 247-250

O’Hegarty M, Pederson LL, Nelson DE, Mowery P, Gable JM, Wortley P. 2006. Reactions of young adult smokers to warning labels on cigarette packages. Am. J. of Preventive Med. 30(6): 467-73

Oster E, Shoulson I, Dorsey R. 2013. Optimal Expectations and Limited Medical Testing: Evidence from Huntington Disease. Am. Econ. Rev. 103(2): 804-30

Pope DG. 2009. Reacting to rankings: Evidence from “America’s Best Hospitals.” J. of Health Econ. 28: 1154-1165

Prat, A. 2005. The wrong kind of transparency. Am. Econ. Rev. 95(3): 862-877.

Ripken S. 2006. The dangers and drawbacks of the disclosure antidote: Toward a more substantive approach to securities regulation. Baylor L. Rev. 58(1): 139-204

Rogers RW. 1975. A protection motivation theory of fear appeals and attitude change. J. of Psych. 91(1), 93-114.

Ross SA. 1973. The economic theory of agency: The principal's problem. Am. Econ. Rev. 63(2): 134-139

Sage WM. 1999. Regulating through information disclosure laws and American health care. Columbia L. Rev. 99(7): 1701-1829

Sah S, Loewenstein G. 2013. Nothing to declare: Mandatory and voluntary disclosure leads advisors to avoid conflicts of interest. Available at SSRN: http://ssrn.com/abstract $=2289975$

Sah S, Loewenstein G, Cain D. 2012. The burden of disclosure: Increased compliance with distrusted advice. J. of Personality and Soc. Psych.: Interpersonal Rel. and Group Processes 104(2): 289-304 
Sah S, Loewenstein G, Cain D. 2013. Insinuation anxiety: increased pressure to follow less trusted advice after disclosure of a conflict of interest. Working Paper, Carnegie Mellon Univeristy.

Schelling T. 1987. The mind as a consuming organ. In The Multiple Self, ed. J. Elster, Cambridge, England: Cambridge Univ. Press

Schultz PW, Nolan JM, Cialdini RB, Goldstein NJ, Griskevicius V. 2007. The constructive, destructive, and reconstructive power of social norms. Psych. Sci. 18(5): 429-434

Schwartz D, Fischhoff B, Krishnamurti T, Sowell F. 2013. The Hawthorne Effect and energy awareness. Proceedings of the National Academy of Sciences: In press

Sharot T. 2011. The optimistic bias. Pantheon.

Shin HS. 2003. Disclosures and asset returns. Econometrica 71(1): 105-133

Sicherman N, Loewenstein G, Seppi D, Utkus S. 2013. Financial attention. Available at SSRN: http://ssrn.com/abstract=2120955 or http://dx.doi.org/10.2139/ssrn.2120955

Simon HA. 1955. A behavioral model of rational choice. QJE 69: 99-118

Sims CA. 2003. Implications of rational inattention. J. Monetary Econ. 50(3): 665-90

Slovic P. 2000. Rejoinder: the perils of Viscusi's analyses of smoking risk perceptions. J. Beh. Dec. Making 13(2): 273-76

Sobani Z, Nizami S, Raz E, ul Ain Baloch N, Khan JA. 2010. Graphic tobacco health warnings: which genre to choose? The International Journal of Tuberculosis and Lung Disease 14(3): 356-61

Sunstein CR. 1999. Informational regulation and informational standing: Akins and beyond. Univ. of Pennsylvania Law Rev. 147(3): 613-675.

Sunstein CR, Thaler R. 2003. Libertarian paternalism is not an oxymoron. Univ. of Chicago L. Rev. 70: 1159-1202

Sunstein CR. 2013. Simpler: The future of government. Simon and Schuster.

Sunstein CR. 2014. Nanny statecraft. Yale University Press.

Teisl MF, Roe B. 1998. The economics of labeling: An overview of issues for health and environmental disclosure. Agricultural and Resource Economics Review, 27: 140-150

Thaler R, Sunstein CR. 2008. Nudge: Improving decisions about health,wealth, and happiness. Yale University Press 
Thorne J, Egan C. 2002. An evaluation of the Federal Trade Commission's EnergyGuide appliance label: final report and recommendations. American Council for an EnergyEfficient Economy, Available at: http://aceee.org/research-report/a021

Thrasher JF, Rousu MC, Hammond D, Navarro A, Corrigan JR. 2011. Estimating the impact of pictorial health warnings and "plain” cigarette packaging: evidence from experimental auctions among adult smokers in the United States. Health Policy 102(1): 41-8

Turow J, Hoofnagle CJ, Mulligan D, Good N, Grossklags J. 2008. The Federal Trade Commission and consumer privacy in the coming decade. I/S: A Journal of Law and Policy for the Information Society 3(3), 723-749

Valley K, Thompson L, Gibbons R, Bazerman MH. 2002. How communication improves efficiency in bargaining games. Econ. Beh. 38(1):127-55

Viscusi WK. 1990. Do smokers underestimate risks? J. Pol. Econ. , 98(6): 1253-69

Waide P. 2004. Energy labeling around the globe. Presented at Energy Labels - a tool for energy agencies 19 October, Brussels.

Wiel S, McMahon JE. 2003. Governments should implement energy-efficiency standards and labels-cautiously. Energy Policy 31(13): 1403-1415

Wisdom J, Downs J, Loewenstein G. 2009. Promoting Healthy Choices: Information vs. Convenience. Am. Econ. J.: Applied 99(2): 159-64

Worsfold D, Worsfold PM. 2007. Evaluating food hygiene inspection schemes: 'Scores on Doors' in the UK. Intl. J. of Consumer Studies 31(6): 582-588 